\title{
MANIFESTO CONTRA A PEC 65: UMA ODE AO MEIO AMBIENTE SADIO
}

\author{
MANIFEST AGAINST PEC 65: \\ AN EXALTATION OF A HEALTHY ENVIRONMENT
}

\author{
Gustavo Medeiros Soares Esteves ${ }^{1}$
}

\section{RESUMO}

O presente artigo alude ao conteúdo do Projeto de Emenda Constitucional número 65 de 2012, bem como a sua justificativa, alertando para a inconstitucionalidade do mesmo. Analisa-se o conceito de desenvolvimento sustentável, demonstrando o giro na percepção ambiental, que deixa de ser antropocêntrica/utilitarista. Constata-se ser o licenciamento ambiental fundamental para a manutenção de um meio ambiente sadio. Ao final, traça-se, efetivamente, as inconstitucionalidades da PEC.

Palavras-chave: PEC Inconstitucional. Desenvolvimento Sustentável. Meio Ambiente Sadio. Fraternidade. Licenciamento.

\begin{abstract}
This paper refers to the content of the Constitutional Amendment Bill number 65 of 2012, as well as its justification, stressing the unconstitutionality of it. It analyzes the concept of sustainable development, demonstrating turning environmental awareness, which is no longer anthropocentric/utilitarian. The environmental licensing is the key for maintaining a healthy environment. Finally, the unconstitutionality of de Amendment are uncovered.
\end{abstract}

Keywords: Unconstitutionality of the Constitucional Amendment Bill. Sustainable Development. Healtht Environment. Fraternity. Licensing.

\footnotetext{
${ }^{1}$ Mestrando em Direitos Humanos pela Universidade Tiradentes - UNIT, Aracaju, Sergipe, (Brasil). Advogado. Tem Experiência na Área de Direito Contencioso Cível e Administrativo, bem como nas áreas de consultoria. E-mail: gustavomse@gmail.com
} 


\section{INTRODUÇÃO}

O presente artigo, por meio de análise teórica, legislativa e jurisprudencial, analisará o conteúdo do Projeto de Emenda Constitucional n ${ }^{\circ} 65$ de 2012 esclarecendo, em um primeiro momento, ser intuito do mesmo acrescer ao art. 225 da Constituição parágrafo que resulta em completa subversão da lógica do licenciamento ambiental. Segundo o que se propõe, a mera apresentação do EIA (Estudo Prévio de Impacto Ambiental) importa em autorização para a execução de obra.

Estaríamos, portanto, diante de um cheque em branco para a instalação de obra ou atividade potencialmente causadora de significativa degradação ao meio ambiente, âmbito do EIA/RIMA.

Num segundo momento, será analisado o conceito de desenvolvimento sustentável, esclarecendo-se as suas vertentes de crescimento econômico, equidade social e preservação ambiental.

Deixar-se-á claro o fato de estarmos passando por grave crise ecológica, fomentada pela industrialização desenfreada e consumismo exacerbado, o que culminou numa visão antropocêntrica do meio ambiente, utilizado a serviço do homem (perspectiva utilitarista).

Fato é que a análise de desenvolvimento com foco somente no crescimento econômico não pode mais ser o mote contemporâneo. O utilitarismo do meio ambiente se enfraquece diante dos movimentos verdes. É o giro ecológico, que teve como marco a Conferência de Estocolmo de 1972, a mola propulsora deste novo olhar para o desenvolvimento, também plasmado no meio ambiente sadio.

Demonstrar-se-á, posteriormente, que a Constituição da República Federativa do Brasil, por meio dos artigos $3^{\circ}$, II; $170, \mathrm{~V}$ e 225 , consagrou o direito fundamental ao desenvolvimento sustentável, tendo a ordem econômica, como princípio de observância, a defesa do meio ambiente.

Ademais, restará evidenciado que a Constituição de 1988 inaugurou o constitucionalismo fraternal, sendo o meio ambiente um direito fraterno. Ao utilizarmos recursos naturais, devemos pensar no próximo e nas futuras gerações.

Ao final, o artigo demonstrará que a PEC 65 é inconstitucional por ferir o art. 60, § $4^{\circ}$, da Constituição, corporificando o malfadado projeto patente a ofensa às cláusulas pétreas, notadamente separação dos poderes e direitos e garantias individuais. 


\section{A PEC 65/2012}

Tramita no Congresso Nacional o projeto de emenda constitucional de número 65 (PEC 65/2012), cujo autor é o Senador Acir Gurgacz do PDT de Roraima. O intuito da proposta é acrescer ao artigo 225 da Carta Constitucional o parágrafo sétimo, que possui a seguinte redação:

A apresentação de estudo prévio de impacto ambiental importa autorização para a execução da obra, que não poderá ser suspensa ou cancelada pelas mesmas razões a não ser em face de fato superveniente. ${ }^{2}$

Fato é que a aludida PEC, como será pormenorizado no decorrer do presente artigo, subverte a lógica do licenciamento ambiental, impactando no meio ambiente sadio e contrariando o princípio do desenvolvimento sustentável.

Ofende, ainda, as cláusulas pétreas consubstanciadas na separação dos poderes e nos direitos e garantias individuais, previstas no artigo 60 , parágrafo $4^{\circ}$, incisos III e IV, respectivamente.

Como senão bastasse o retrocesso que imprimi, a justificativa da PEC é pior ainda. Finca o pé no argumento de existência de obras inacabadas e interrompidas mediante decisão judicial:

Uma das maiores dificuldades da Administração Pública brasileira, e, também umas das razões principais para o seu desprestígio, que se revela à sociedade como manifestação pública de ineficiência, consiste nas obras inacabadas ou nas obras ou ações que se iniciam e são a seguir interrompidas mediante decisão judicial de natureza cautelar ou liminar, resultantes, muitas vezes, de ações judiciais protelatórias. ${ }^{3}$

Ao Poder Judiciário é dado o pronunciamento quando provocado. Se, ao apreciar determinado caso concreto, entende por bem conceder liminar é porque vislumbra na hipótese dano irreparável e de difícil reparação, fumaça do bom direito e perigo na demora. Não há como se impedir o acesso ao judiciário, sob pena de se quebrar a lógica da Separação dos Poderes. Se com licenciamento vemos atrocidades ocorrendo todos os dias - como demonstram as matérias jornalísticas e a prática do dia a dia -, imagine sem o referido procedimento.

\footnotetext{
${ }^{2}$ Texto extraído de documento do Senado Federal referente à PEC 65.

${ }^{3}$ Texto extraído da justificativa da PEC 65.
} 
A PEC, inadvertidamente, representa um cheque em branco para a instalação de obra ou atividade potencialmente causadora de significativa degradação ao meio ambiente, âmbito do EIA/RIMA. O devido licenciamento ambiental é imperioso, prevenindo e precavendo danos ambientais.

\section{DESENVOLVIMENTO SUSTENTÁVEL E MEIO AMBIENTE SADIO}

O conceito de desenvolvimento humano sustentável é amplo e visa a garantir a vida biológica, bem como a dignidade e qualidade de vida para as presentes e futuras gerações (RESENDE, 2015, p. 36).

As suas vertentes são o crescimento econômico, a equidade social e a preservação ambiental:

Em linhas gerais, pode-se afirmar que a sustentabilidade econômica impõe eficiência social na alocação e gestão de recursos públicos, a sustentabilidade social exige um processo de desenvolvimento que promova a justiça distributiva e a maximização da eficácia dos direitos humanos sociais e, por fim, a sustentabilidade ambiental pugna pela implementação de uma justiça ambiental intergeracional, preocupando-se com os impactos negativos das atividades humanas no meio ambiente, a fim de que o desenvolvimento permita às gerações futuras o acesso a um meio ambiente sadio e necessário à qualidade de vida (RESENDE, 2015, p. 39-40).

Aqui, a reflexão se aterá mais ao aspecto da preservação ambiental.

Está claro que, nos últimos tempos, estamos passando por uma grave crise ecológica. A industrialização desenfreada catapultada, sobretudo, após o fim da $2^{\mathrm{a}}$ Guerra Mundial e a sociedade de consumo contribuíram sensivelmente para a situação enfrentada na atualidade. É nesse sentido que o desenvolvimento sustentável é fundamental para a manutenção de um meio ambiente ecologicamente equilibrado.

O consumismo desenfreado, gerador de lixo e poluição ao meio ambiente, é cada vez mais fomentado. De acordo Bauman, em seu livro Vida para Consumo, importa para o mercado que o cliente não esteja plenamente satisfeito, devendo sempre buscar algo a mais para a sua satisfação:

A sociedade de consumo tem como base de suas alegações a promessa de satisfazer os desejos humanos em um grau que nenhuma sociedade do passado pôde alcançar, ou mesmo sonhar, mas a promessa de satisfação só permanece sedutora enquanto o desejo continua insatisfeito; mais importante 
ainda, quando o cliente não está plenamente satisfeito - ou seja, enquanto não se acredita que os desejos que motivaram e colocaram em movimento a busca da satisfação e estimularam experimentos consumistas tenham sido verdadeira e totalmente realizados (BAUMAN, 2008, p. 63).

A consciência da população tem que mudar. Caso contrário, corremos sério risco de sofrermos catástrofes ambientais nas próximas décadas.

Até bem pouco tempo atrás, a preocupação esteve centrada tão e somente no aspecto econômico do desenvolvimento. Muito se poluiu e devastou florestas em detrimento de um meio ambiente ecologicamente equilibrado.

No século passado, mais precisamente até a década de 60, imperou o tratamento do meio ambiente numa perspectiva antropocêntrica, resvalando na utilização da natureza a serviço do homem (utilitarismo).

Novo rumo foi traçado, no século XX, a partir da década de 70 , ocasião em que emergiram os movimentos verdes. Marco histórico deste giro ecológico foi a realização da Conferência de Estocolmo de 1972 sobre o meio ambiente. Nela, conseguiu-se visualizar larga preocupação com a sustentabilidade do meio ambiente, como se pode notar pela leitura de seus princípios 1, 2, 5 e 13, por exemplo (MACHADO, 2014, p. 72):

A Conferência de Estocolmo trata, em diversos princípios, da questão do desenvolvimento ligado ao meio ambiente: o homem é portador solene da obrigação de proteger e melhorar o meio ambiente, para as presentes e futuras (princípio 1); os recursos não renováveis da Terra devem ser utilizados de forma a evitar o seu esgotamento futuro (princípio 5); deve ser realizado um planejamento adequado e integrado, com ordenamento mais racional, para a preservação do ar, do solo, da fauna, da flora e dos ecossistemas naturais (princípios $2 e$ 13), valorizando-se a planificação dos agrupamentos humanos e da urbanização, a maximização e a repartição dos benefícios sociais, econômicos e ambientais.

Mais tarde, em 1983, foi criada a Comissão Mundial sobre Meio Ambiente e Desenvolvimento, proposta pela Assembleia Geral das Nações Unidas. Dela resultou o relatório Brundtland, publicado em 1987. É este relatório quem traz uma das definições mais difundidas de desenvolvimento sustentável (RESENDE, 2015, p. 38) como sendo:

Aquele que satisfaz as necessidades presentes, sem comprometer a capacidade das gerações futuras de suprir as suas próprias 
necessidades, oferecendo uma perspectiva diferenciada da questão ambiental e do desenvolvimento.

Os laços do meio ambiente com o desenvolvimento foram estreitados após a Declaração Rio de Janeiro de 1992, a chamada ECO 92, que trouxe 11 (onze) princípios, mencionando o termo desenvolvimento sustentável de forma expressa (MACHADO, 2014, p. 74).

Partindo para o âmbito interno, a nossa Constituição da República Federativa do Brasil enaltece, em seu preâmbulo, o compromisso do Estado democrático brasileiro em assegurar o desenvolvimento da sociedade brasileira ${ }^{4}$. Logo após, o seu art. $3^{\circ}$, inciso II, traça como um dos objetivos fundamentais de nossa federação a garantia do desenvolvimento nacional. O aludido dispositivo "não determina quais os contornos do desenvolvimento almejado pelo constituinte originário, ou ainda, quais os instrumentos para efetivá-lo e nem como os cidadãos podem exigir-lhe o cumprimento." (PEIXINHO, FERRARO, 2016). Assim, somente uma leitura de todo o texto constitucional, alinhando todos os seus dispositivos, dão conta de que a ordem econômica, que objetiva a existência digna de todos, tem como princípio de observância a defesa do meio ambiente (art. 170, VI ${ }^{5}$ ). Ou seja, o crescimento econômico tem que estar aliado à proteção do meio ambiente, não podendo a economia crescer a qualquer custo.

O conceito de desenvolvimento econômico mudou, sendo certo que não mais está atrelado somente à elevação do PIB (Produto Interno Bruto), maximização de renda ou riqueza. Este é o enfoque dado por Amartya Sen, economista indiano que delineou a ideia de desenvolvimento como liberdade:

Procuramos mostrar neste livro que o desenvolvimento poder ser visto como um processo de expansão das liberdades reais que as pessoas desfrutam. $\mathrm{O}$ enfoque nas liberdades humanas contrasta com visões mais restritas de

\footnotetext{
${ }^{4}$ Preâmbulo da Constituição: Nós, representantes do povo brasileiro, reunidos em Assembléia Nacional Constituinte para instituir um Estado Democrático, destinado a assegurar o exercício dos direitos sociais e individuais, a liberdade, a segurança, o bem-estar, o desenvolvimento, a igualdade e a justiça como valores supremos de uma sociedade fraterna, pluralista e sem preconceitos, fundada na harmonia social e comprometida, na ordem interna e internacional, com a solução pacífica das controvérsias, promulgamos, sob a proteção de Deus, a seguinte Constituição da República Federativa do Brasil.

${ }^{5}$ Art. 170. A ordem econômica, fundada na valorização do trabalho humano e na livre iniciativa, tem por fim assegurar a todos existência digna, conforme os ditames da justiça social, observados os seguintes princípios: (...)VI - defesa do meio ambiente, inclusive mediante tratamento diferenciado conforme o impacto ambiental dos produtos e serviços e de seus processos de elaboração e prestação; (Redação dada pela Emenda Constitucional n ${ }^{\circ}$ 42 , de 19.12.2003)
} 
desenvolvimento, como as que identificam desenvolvimento com crescimento do Produto Nacional Bruto (PNB), aumento de rendas pessoais, industrialização, avanço tecnológico ou modernização social. O crescimento do PNB ou das rendas individuais obviamente pode ser muito importante como um meio de expandir as liberdades desfrutadas pelos membros da sociedade. Mas as liberdades dependem também de outros determinantes, como as disposições sociais e econômicas (por exemplo, os serviços de educação e saúde) e os direitos civis (por exemplo, a liberdade de participar de discussões e averiguações públicas). (SEN, 2010, p. 16)

É neste sentido que se percebe, de forma ainda mais nítida, a íntima relação que deve existir entre desenvolvimento econômico e meio ambiente. Basta, aqui, lembrar do recente caso envolvendo o desastre ambiental de rompimento da barragem da mineradora SAMARCO. A população diretamente atingida pela lama tóxica até hoje encontra-se restrita em seus meios de sobrevivência, não tendo mais meios de prover o seu próprio sustento. Muitos perderam as suas moradias. Evidente que os maus tratos ao meio ambiente podem impactar a vida das pessoas, sobretudo a economia de determinado lugar.

O meio ambiente ecologicamente equilibrado (sadio) é condição sine qua non para uma sadia qualidade de vida, devendo ser protegido para as presentes e futuras gerações, assim como preconiza o caput do art. 225 da Carta Constitucional.

Conjugando-se o preâmbulo da nossa Carta Magna com os seus artigos $3^{\circ}$, II; 170, VI e 225 podemos concluir que se consagrou no país um direito fundamental ao desenvolvimento sustentável.

Aliás, internacionalmente, já se reconhecia a existência de um direito fundamental ao desenvolvimento.

Primeiro, a consagração se deu na Carta Africana de Direitos Humanos e dos Povos de janeiro de 1981.

Após, a ONU, em 1986, adotou a Declaração sobre o Direito ao Desenvolvimento. O seu artigo 1, item 1, trouxe, expressamente, o direito ao desenvolvimento à categoria de direito humano inalienável:

O direito ao desenvolvimento é um direito humano inalienável em virtude do qual toda pessoa humana e todos os povos estão habilitados a participar do desenvolvimento econômico, social, cultural e político, a ele contribuir e dele desfrutar, no qual todos os direitos humanos e liberdade fundamentais possam ser plenamente realizados. ${ }^{6}$

\footnotetext{
${ }^{6}$ Texto extraído da Declaração sobre o Direito ao Desenvolvimento.
} 
Ainda sobre a Declaração sobre o Direito ao Desenvolvimento, o item 1 do art. $8^{\circ}$ traz conotação de desenvolvimento sustentável ao dispor que:

Os Estados devem tomar, a nível nacional, todas as medidas necessárias para a realização do direito ao desenvolvimento e devem assegurar, inter alia, igualdade de oportunidade para todas em seu acesso aos recursos básicos, educação, serviços de saúde, alimentação, habitação, emprego e distribuição equitativa da renda. ${ }^{7}$

Por fim, a Declaração e Programa de Ação de Viena das Nações Unidas, de 1993, condecorou o direito ao desenvolvimento como um direito universal, fundamental e inalienável (RESENDE, 2015, p. 40-41).

Patente a existência de um direito fundamental ao desenvolvimento sustentável, não se pode mais compactuar com condutas infringentes do meio ambiente, sobretudo aquelas que visam a expurgar do ordenamento jurídico o devido licenciamento ambiental.

Tratando-se bem o meio ambiente, cuida-se bem de todos, haja vista estarmos diante de um direito de terceira dimensão, que atinge a coletividade em sua completude. Não podemos olvidar que a Constituição de 1988 inaugurou no Brasil o constitucionalismo fraternal. Não é à toa que foi trazido como objetivo da República Federativa a construção de uma sociedade livre (dimensão liberal), justa (dimensão social) e solidária (dimensão fraternal).

O meio ambiente é um direito fraternal. Quando utilizamos recursos naturais, devemos pensar no próximo, bem como nas futuras gerações. Ao se privilegiar a proteção ao meio ambiente, com todos atuando em prol de um ecossistema sadio, estaremos vivendo em comunhão, mote do constitucionalismo fraternal:

A Constituição busca, assim, com a dimensão fraternal, uma integração comunitária, uma vida em comunhão. Se as pessoas viverem em comunidade, estarão, de fato, numa comum unidade. Em uma palavra: fraternidade. (MACHADO, 2010, p. 100)

Somos responsáveis uns pelos outros. Não devemos fazer com o próximo aquilo que não gostaríamos que fizessem conosco (MACHADO, 2010, p. 105).

É chegada a hora de unirmos nossas forças para o bem-estar da humanidade em sua totalidade. Um empresariado que polui o meio ambiente o faz em detrimento dele próprio e

${ }^{7}$ Texto extraído da Declaração sobre o Direito ao Desenvolvimento. 
do seu semelhante. O mesmo se pode dizer, guardadas as devidas proporções, de uma pessoa física que joga lixo no chão. O mundo, em crise ecológica, urge por cidadãos que hajam com consciência limpa, limpa no sentido literal mesmo, qual seja: de não poluição do meio ambiente, de se preocupar com o próximo, de se preocupar com o ecossistema, de se preocupar com o que é nosso. Somos todos componentes do mesmo barco e devemos remar no mesmo sentido, na mesma cadência, na mesma direção. Uma remada em falso, um desvio de curso, prejudica a todos na mesma proporção. Devemos, juntos, lutar por uma rota retilínea, limpa, de águas tranquilas. Qualquer movimento em falso poderá colocar tudo a perder e o barco, desgovernado, tomar um caminho sem volta.

A PEC 65, como se pormenorizará adiante, impõe ao arcabouço jurídico-ambiental nacional enorme retrocesso. A sua aprovação desviará o rumo traçado nos últimos anos pelo movimento verde e pelo licenciamento ambiental. Deixar que isso aconteça é uma temeridade.

\section{INCONSTITUCIONALIDADE DA PEC 65}

Notório que se admite, no Brasil, o controle de constitucionalidade de Emenda Constitucional, o qual é exercido sobre a atuação do constituinte derivado. É o propalado controle repressivo.

Ocorre que há muito já se admite o controle preventivo de constitucionalidade das emendas constitucionais. Esta interpretação advém do art. 60, parágrafo $4^{\circ}$, da Constituição, que abriga as famosas cláusulas pétreas. De acordo com o preceito em questão, não se pode deliberar proposta de emenda que tenda a abolir (i) a forma federativa de Estado; (ii) o voto direto, secreto, universal e periódico; (iii) a separação dos poderes e (iv) os direitos e garantidas individuais. A forma de insurgência contra emenda violadora destas prerrogativas é, segundo a Corte Constitucional, a impetração de mandado de segurança por parlamentar (SARLET, MARINONI, MITIDIERO, 2015, p. 931):

O STF admite o controle judicial do processo legislativo em nome do direito subjetivo do parlamentar de impedir que a elaboração dos atos normativos incida em desvios inconstitucionais. Entende-se caber mandado de segurança - portanto controle incidental - quando a vedação constitucional se dirige ao próprio processamento da lei ou da emenda. 
A PEC 65 é inconstitucional e, portanto, deve ser barrada antes de se transformar em emenda constitucional.

De acordo com a redação apresentada, a execução das obras passa a ser autorizada com a simples apresentação do EIA/RIMA, pouco importando a análise dos órgãos licenciadores. Ademais, é vedada a revisão administrativa e judicial. Isto é: estamos diante de uma temeridade, de uma excrescência. Patente a violação aos incisos III e IV do $\S 4^{\circ}$ do art. 60 da nossa lei maior, mais precisamente separação dos poderes e direitos e garantidas individuais.

O direito ao meio ambiente ecologicamente equilibrado (CR, art. 225, caput) integra, conforme mencionado anteriormente no artigo, o rol dos direitos humanos, dos direitos fundamentais, o que é reconhecido em âmbito internacional e nacional:

O reconhecimento da proteção ambiental como parte dos direitos humanos remonta à Declaração de Estocolmo, em 1972, quando o meio ambiente começou a deixar de ser visto como algo dissociado da humanidade. Nesse sentido, o Princípio I daquela Declaração definia que 'o homem tem o direito fundamental à liberdade, à igualdade e ao desfrute de condições de vida adequadas em um meio ambiente de qualidade tal que lhe permita levar uma vida digna e gozar de bem estar'.

Posteriormente, o Princípio 10 da Declaração do Rio de Janeiro sobre Meio Ambiente e Desenvolvimento, de 1992, veio a conferir destaque ao direito de a pessoa participar no processo decisório relativo a questões ambientais e de ter acesso a informações sobre matéria de meio ambiente, norma que vai aparecer em diversos tratados posteriores, como a Convenção das Nações Unidas sobre Mudança do Clima e o Protocolo de Cartagena. A Convenção sobre a Diversidade Biológica, de 1992, veio a reconhecer o direito das presentes e futuras gerações à preservação da biosfera.

(...) No direito interno brasileiro, também é reconhecida a ligação entre os direitos humanos e o meio ambiente, como se infere do artigo 225 da Constituição Federal, que reza que 'todos têm direito ao meio ambiente ecologicamente equilibrado, bem de uso comum do povo e essencial à sadia qualidade de vida'. Em outras palavras: a vida em condições de dignidade depende da proteção ao meio ambiente. (PORTELA, 2011, p. 397)

Todos nós brasileiros temos, portanto, direito fundamental a um meio ambiente ecologicamente equilibrado, o qual não pode ser suprimido por meio do referido projeto de emenda constitucional 65. A simples apresentação de EIA não é suficiente para se permitir a imediata execução de uma obra, sobretudo naqueles empreendimentos reputados de largo impacto ambiental, onde se exige o aludido estudo. A PEC negligencia, ainda, as etapas de licenciamento ambiental traçadas no nosso ordenamento jurídico, fundamentais para um 
desenvolvimento sustentável, quais sejam: licença prévia, licença de instalação e licença de operação, indispensáveis para obras de significativo impacto ambiental.

O EIA é um estudo técnico de planejamento e não uma licença ou autorização para execução de empreendimento ou obra. O seu intuito é averiguar as implicações ambientais antes da realização de obras e atividades que possam repercutir negativamente no meio ambiente. Ou seja: o EIA subsidia o procedimento de licenciamento ambiental. Contudo, não é o licenciamento em si.

Tal estudo deverá ser analisado pelos órgãos competentes de controle, seguindo o trâmite normal das etapas supramencionadas. Também, o aludido estudo técnico deverá ser analisado pela população interessada, via consulta ou audiências públicas. Autorizar a efetivação de empreendimento ou obra sem que os mesmos passem pelo trâmite processual administrativo de praxe é subverter toda a lógica de licenciamento existente no nosso ordenamento.

O EIA não é o licenciamento, mas sim um dos documentos que guarnecem o procedimento de licenciamento ambiental para as atividades consideradas efetiva ou potencialmente causadoras de significativa degradação ambiental ${ }^{8}$. A PEC 65 pretende justamente autorizar a atividade ou obra sem que se percorra todo o trâmite procedimental necessário para, ao final, preenchidos todos os requisitos, ser concedida a licença ambiental.

Todo o percurso da licença ambiental - licença prévia, licença de instalação e licença de operação ${ }^{9}$ - é fundamental, sobretudo nos casos em que se exige EIA. O intuito do EIA é justamente fornecer aos órgãos licenciadores informações para a formação do convencimento dos mesmos. Percorrer-se-á todo o procedimento administrativo de licenciamento ambiental, que poderá culminar com a licença ambiental, se assim se entender pertinente. Sobre este papel do EIA, de fornecimento de convencimento às autoridades licenciadoras, Paulo Affonso Leme Machado traz importante ensinamento da doutrina estrangeira:

\footnotetext{
${ }^{8}$ Sobre empreendimentos e atividades efetiva ou potencialmente causadoras de significativa degradação ambiental a Resolução CONAMA $237 / 97$ disciplina no seu art. $3^{\circ}$. A licença ambiental para empreendimentos e atividades consideradas efetiva ou potencialmente causadoras de significativa degradação do meio dependerá de prévio estudo de impacto ambiental e respectivo relatório de impacto sobre o meio ambiente (EIA/RIMA), ao qual dar-se-á publicidade, garantida a realização de audiências públicas, quando couber, de acordo com a regulamentação.

${ }^{9} \mathrm{O}$ texto da Resolução CONAMA 237/97, art. $1^{\text {o }}$, I, aduz que licenciamento ambiental é o procedimento administrativo pelo qual o órgão ambiental competente licencia a localização, instalação, ampliação e a operação de empreendimentos e atividades utilizadoras de recursos ambientais, consideras efetiva ou potencialmente poluidoras ou daquelas que, sob qualquer forma, possam causar degradação ambiental, considerando as disposições legais e regulamentares e as normas técnicas aplicáveis ao caso.
} 
A função do procedimento de avaliação não é influenciar as decisões administrativas sistematicamente a favor das considerações ambientais, em detrimento das vantagens econômicas e sociais suscetíveis de advirem de um projeto. $O$ objetivo é dar 'às Administrações Públicas uma base séria de informação, de modo a poder pesar os interesses em jogo, quando da tomada de decisão, inclusive aqueles do ambiente, tendo em vista uma finalidade superior', como acentua J. F. Chambault. (2014, p. 267).

O fornecimento de EIA não implica em licenciamento ambiental, pretensão que a PEC 65 pretende referendar ao arrepio da Constituição, das Leis e Resoluções que regulamentam o procedimento de licenciamento ambiental no Brasil. Tal pretensão visa a suprimir núcleo essencial do direito fundamental ao meio ambiente ecologicamente equilibrado, o que não pode ser admitido.

Enaltecendo a importância do cumprimento das etapas do licenciamento ambiental, o Ministério Público Federal emitiu Nota Técnica em que atacou os termos da PEC 65, no seguinte sentido:

O licenciamento ambiental é um procedimento do qual faz parte o EIA, o RIMA, o 'relatório de ausência de impacto ambiental significativo' (RAIAS) e a licença ambiental propriamente dita. É um dos instrumentos da Política Nacional do Meio Ambiente, nos termos do artigo $9^{\circ}$, inciso IV, da Lei 6.938/81 e tem como objetivo primordial a preservação e a conservação do meio ambiente (art. $2^{\circ}$ caput). Dessa forma, tem que ser utilizado sempre e permanentemente para atender a esse fim específico do PNMA.

Tal procedimento administrativo, por sua vez, desenvolve-se em três fases, não se limitando a uma só licença expedida em um único momento. Nele estão previstas três etapas para a implantação de um empreendimento potencialmente degradador do meio ambiente, a cada uma dessas etapas correspondendo uma licença específica, expedida pelo Poder Público. São elas:

a)Licença Prévia - LP: concedida na etapa inicial do licenciamento. É a fase preliminar de planejamento da atividade, em que o empreendedor manifesta a sua intenção de realizar um determinado empreendimento, sendo então elaborados os estudos de viabilidade do projeto (entre eles o estudo de impacto ambiental). Analisados, discutidos e aprovados esses estudos iniciais, o órgão administrativo ambiental expede a LP, passando à segunda etapa;

b)Licença de Instalação - LI: concedida na fase de elaboração do Projeto Executivo, que é um projeto mais detalhado e no qual são fixadas as prescrições de natureza técnica, capazes de compatibilizar a instalação do empreendimento com a proteção do meio ambiente;

c)Licença de Operação - LO: autoriza a operação da atividade ou empreendimento, após a verificação do efetivo cumprimento do que consta das licenças anteriores; 
Portanto, como enfatiza Álvaro Luiz Valery Mirra, em obra aqui já referida, 'o licenciamento ambiental pressupõe três etapas e a expedição de três licenças, necessária e sucessivamente. Isto significa que não se pode suprimir nenhuma dessas etapas e nem se pode iniciar uma nova etapa antes do encerramento da etapa anterior, com a correspondente concessão da licença cabível, sob pena de configurar-se flagrante ilegalidade no exercício da atividade'.

Continua aquele autor esclarecendo que 'este é um momento importante em que pode aparecer a necessidade de controle desses atos do Poder Público. De fato, não é raro que um empreendedor acabe atropelando esse processo e se antecipando a uma ou outra das etapas, antes de obter a licença para tanto. Tampouco se pode afastar a possibilidade de o Poder Público conceder uma ou mais dessas licenças antes de terminada a fase própria que enseja a sua outorga. Num caso e no outro a atividade será ilegal e poderá (deverá) ser impugnada ou embargada. ${ }^{, 10}$

Além de a PEC 65 pretender abolir direito fundamental ao meio ambiente ecologicamente equilibrado, incidindo em afronta ao inciso IV, $\S 4^{\circ}$, do art. 60 da Constituição Federal, patente também que a sua redação confronta com o inciso III, $\S 4^{\circ}$, do art. 60 da Carta Magna, que trata da separação dos poderes.

De acordo com a PEC 65, a redação do $\S 7^{\circ}$ do art. 225 da Constituição Federal informa que a apresentação de EIA reflete em autorização para execução de obra, "que não poderá ser suspensa ou cancelada pelas mesmas razões a não ser em face de fato superveniente".

O que pretende a PEC é suprimir da apreciação do Poder Judiciário a análise da regularidade na execução das obras/empreendimentos, afastando-se a possibilidade de paralisação por decisão judicial. Isso fica bem claro quando aludimos neste texto à justificativa da PEC, que se embasa na existência de obras inacabadas e interrompidas mediante decisão judicial.

O legislador constituinte estabeleceu, no inciso XXXV do art. $5^{\circ}$ da Constituição, o princípio da inafastabilidade do controle jurisdicional, sendo que a redação do $\S 7^{\circ}$ do art. 225, como pretende estabelecer a PEC, faz dele letra morta. A aniquilação desta função típica do Poder Judiciário implica em afronta à separação dos poderes.

Para além de impedir a apreciação do Poder Judiciário, a redação da PEC também frustra a atuação dos órgãos de controle e fiscalização, seja ela da própria administração

\footnotetext{
10 Texto extraído da Nota Técnica sobre a PEC 65/2012 e as Cláusulas Pétreas, emitida em 03.05.2016 pelo Ministério Público Federal, Grupo de Trabalho Intercameral - $4^{\mathrm{a}}$ Câmara de Coordenação e Revisão, $6^{\mathrm{a}}$ Câmara de Coordenação e Revisão, Procuradoria Federal dos Direitos do Cidadão.
} 
pública, seja do Ministério Público. Mais um ponto da PEC que importa em ofensa à separação dos poderes.

Caso, absurdamente, esta PEC passe, ainda temos a via da Ação Direita de Inconstitucionalidade para tentar barrar esta excrecência.

\section{CONCLUSÕES}

Considerando o desenrolar do presente artigo, não existe lugar para a PEC 65 no ordenamento jurídico brasileiro. O seu conteúdo, ao permitir a execução da obra pelo empreendedor com a mera apresentação do Estudo Prévio de Impacto Ambiental, vai de encontro à lógica procedimental do licenciamento ambiental, fazendo letra morta dos princípios da prevenção e da precaução.

O licenciamento ambiental revela procedimento fundamental para a concretização do desenvolvimento sustentável. Transformando-se o mesmo em letra morta, que é o que pretende fazer a PEC 65, as chances de devastação ambiental tomarão proporções catastróficas.

O desenvolvimento sustentável visa a garantir a qualidade de vida para as presentes e futuras gerações. Ao se corporificar os mandamentos do aludido projeto, corremos o risco de deixar um meio ambiente inabitável para as próximas gerações.

A crise ecológica que enfrentamos na atualidade, fruto de um capitalismo pujante, bem como de uma sociedade extremamente consumista, ganhou, desde a década de 70 do século passado, grupos verdes vocacionados a exterminá-la. Os movimentos verdes não podem perder força. Seria um desmesurado retrocesso, o qual temos que coibir.

Numa interpretação sistemática da Constituição, coadunando-se o preâmbulo com os seus arts. $3^{\circ}$, II; 170, VI e 225, percebemos que o constituinte consagrou o direito fundamental ao desenvolvimento sustentável, sendo o mesmo cláusula pétrea incrustrada no art. 60, parágrafo $4^{\circ}$, inciso IV. O meio ambiente ecologicamente equilibrado é fundamental para uma sadia qualidade de vida de todos.

Também, não podemos esquecer que o meio ambiente é um direito fraternal. Ao fazermos uso dos recursos naturais, devemos pensar nos demais cidadãos e nas presentes e futuras gerações. Só assim estaremos vivendo em comunhão e em paz com o meio ambiente.

Todos nós brasileiros possuímos um direito fundamental a um meio ambiente ecologicamente equilibrado, que não pode ser expurgando em função da malfadada PEC 65. 
Definitivamente, a simples apresentação do EIA não é suficiente para se permitir a imediata execução de uma obra. As etapas do licenciamento ambiental não podem ser vilipendiadas (licença prévia, licença de instalação e licença de operação).

O EIA não representa uma licença ambiental, mas sim um estudo técnico de planejamento, que tem por fim verificar as implicações ambientais antes da realização de empreendimentos que possam gerar danos ao meio ambiente.

A PEC 65, do jeito que está formulada, abolirá o direito fundamental ao meio ambiente ecologicamente equilibrado, incidindo em afronta à cláusula pétrea consubstanciada no inciso IV, § $4^{\circ}$, do art. 60 da Constituição.

Ademais, afronta também a cláusula pétrea da Separação dos Poderes prevista no inciso III do diploma legal referido no parágrafo anterior. A PEC suprimirá da apreciação do Poder Judiciário a análise da regularidade na execução das obras/empreendimentos, contrariando o que dispõe o inciso XXXV do art. $5^{\circ}$ da Constituição, que nos conduz ao princípio da inafastabilidade do controle jurisdicional. Também, frustrará a atuação dos órgãos de controle e fiscalização, seja ela da própria administração pública, seja do Ministério Público.

Não podemos compactuar com desmesurado desatino do Congresso Nacional. Lutemos pela rejeição da PEC.

\section{REFERÊNCIAS}

BAUMAN, Zygmunt. Vida para consumo. Rio de Janeiro: Jorge Zahar Editor, 2008.

BRASIL. Constituição da República Federativa do Brasil. Brasília: Senado Federal, 1988.

BRASIL. Proposta de Emenda Constitucional no 65/2012. Disponível em: https://www25.senado.leg.br/web/atividade/materias/-/materia/109736. Arquivo capturado em: 10/06/2016.

BRASIL. Ministério do Meio Ambiente, Conselho Nacional do Meio Ambiente, CONAMA. Resolução CONAMA no 237, de 19 de dezembro de 1997. 
MACHADO, Carlos Augusto Alcântara. Fraternidade como categoria constitucional. In: Princípios Humanistas Constitucionais: reflexões sobre o humanismo do Século XXI, p. 83110. São Paulo: Letras Jurídicas, 2010.

MACHADO, Paulo Affonso Leme. Direito ambiental brasileiro. $22^{\mathrm{a}}$ ed. - São Paulo: Malheiros, 2014.

NOTA tÉCNICA DO MiNistéRIO PÚBliCO FEDERAL. A PEC 65/2012 e as cláusulas pétreas. Disponível em http://www.mpf.mp.br/pgr/documentos/nota-tecnica-pec-652012/. Arquivo capturado em 25/05/2016.

ORGANIZAÇÕES DAS NAÇÕES UNIDAS. Declaração sobre o direito ao desenvolvimento. 1986. Disponível em: <http://www.direitoshumanos.usp.br/index.php/Direitoao-Desenvolvimento/declaracao-sobre-o-direito-ao-desenvolvimento.html $>$. Arquivo capturado em 15/06/2016.

PEIXINHO, Manoel Messias; FERRARO, Suzani Andrade. Direito ao desenvolvimento como direito fundamental. In: XVI Congresso Nacional do CONPEDI. 2007. p. 6963. Disponível em: <http://www.publicadireito.com.br/conpedi/manaus/arquivos/anais/bh/manoel_messias_peixinho. pdf>. Arquivo capturado em 14 de junho de 2016.

PORTELA, Paulo Henrique Gonçalvez. Direito internacional público e privado. $3^{\mathrm{a}} \mathrm{ed}$. - Salvador: JusPodivm, 2011.

RESENDE, Augusto César Leite de. A tutela jurisdicional do direito humano ao meio ambiente sadio perante a corte interamericana de direitos humanos. Belo Horizonte: Fórum, 2015.

SARLET, Ingo Wolfgang; MARINONI, Luiz Guilherme; MITIDIERO, Daniel. Curso de Direito Constitucional. $4^{\mathrm{a}}$ ed. - São Paulo: Saraiva, 2015.

SEN, Amartya. Desenvolvimento como liberdade; tradução Laura Teixeira Motta; revisão técnica Ricardo Doninelli Mendes. São Paulo: Companhia das Letras, 2010. 